\title{
Foreword: responsible innovation in the private sector
}

\section{Introduction to responsible innovation}

Responsible Innovation is an emerging concept concerning the governance of socio-ethical aspects of research and innovation practices. Von Schomberg for instance defines responsible innovation as a 'transparent, interactive process by which societal actors and innovators become mutually responsive to each other with a view to the (ethical) acceptability, sustainability and societal desirability of the innovation process and its marketable products (in order to allow a proper embedding of scientific and technological advances in our society)' (Von Schomberg, 2013, p. 19). It originally emerged in the context of research policies as a result of societal concerns regarding publicly funded research in controversial technologies (cf. Stilgoe et al., 2013). Emerging technologies such as nanotechnologies, big data, alternative energy production and genomics have a history of dispute and societal debate about their ethical desirability, and raises the question whether public funding in research in the field of these controversial technological is political legitimate or not (Collingridge, 1980; Groves, 2006).

An early example of such a controversial technology is the Manhattan project during World War II, that produced the first nuclear weapons. Many people involved did not know the purpose of the research and once they saw the devastating impact it had on Hiroshima and Nagasaki, it amazed both the workers of the Manhattan Project and the rest of the world; many of the researchers involved in the project would not have wanted to contribute to the development of such a devastating bomb, but they didn't know the ultimate purpose of their research (Life, 1945). Nuclear technology is however only called controversial because it also has significant positive applications and positive effects on the social well-being of people in society. Such positive impacts can be seen in enhanced medical treatments, the development of new materials and its provision of a (still debatable) source of energy (NEA, 1993).

Because of these positive and negative possible impacts of new discoveries, policy makers look for ways to influence and govern publicly funded research and innovation in order to achieve innovation outcomes which are sustainable, societal desirable and ethical acceptable (Von Schomberg, 2013); governance of research and innovation can prevent negative outcomes of research and innovation from being implemented in society, and can further positive outcomes through incentive mechanisms.

It is in this context, that responsible research and innovation became interesting for policy makers. In particular European policymakers argued that publicly funded research and innovation should also contribute to the grand challenges of our society, like aging of people, lifestyle diseases like obesity, food safety and food security, sustainable energy, health, well-being and climate change (European Commission, 2011). To achieve this, the European Commission has formulated the Horizon 2020 research framework that addresses the policy priorities of research and innovation related to these grand challenges. This research framework guides the funding of research at the EU level, and many national, local and regional policymakers follow this strategy in their innovation support policies.

Because the concept of responsible innovation is relatively new and still evolving in different directions (Owen et al., 2013; Van den Hoven et al., 2012), there are several underresearched areas in this emerging field of research. To date, research in responsible innovation has mainly examined the 'what' question (i.e. Stilgoe et al., 2013) and the 'why' question, (i.e. van den Hoven et al., 2012), i.e. the reasons why responsible innovation is important. Furthermore, most research is done from a policy or socio-ethical perspective and focusing on academic R\&D environments, while most innovations take place in the private sector. It is precisely responsible innovation in the private sector, which is underrepresented in current research.

Responsible innovation cannot be identified with social or societal innovation upfront, nor with corporate social responsibility (CSR) Pavie et al., 2014). This raises the question how responsible innovation in the private sector can be characterized. To what extend is the concept of responsible innovation applicable in the business context (Blok and Lemmens, 2015)? What are the drivers and barriers of industrial responsible innovation practices (Blok et al., 2015)? Waldman and Galvin (2008) for instance claim 
that responsible leaders combine economic orientations with an extended stakeholder orientation. The business objective shifts to optimizing the economic, social and environmental values in order to bring sustainable value for business and society. Waldman and Siegel (2008) stress, however, that responsibility exists only if there is 'a clear and directly foreseeable return on investment'. The central problem remains that for the short term, strict cost-benefits analyses are more accurate, but projections tend to become more difficult with respect to responsibility in the long term (Blok and Lemmens, 2015; Pless et al., 2012).

Given the importance of the emerging field of responsible innovation and the important role of innovation in the private sector, this special issue of Journal on Chain and Network Science aims to deepen management scholars' and practitioners' understanding of how firms can effectively be involved in responsible innovation processes in order to add social and economic value. The following trends and developments in management studies can help to conceptualize responsible innovation in the private sector.

\section{Breakthrough innovation and the role of markets}

The development of new innovations, in particular breakthrough innovations, goes hand in hand with considerable risks and uncertainties. Not only on the part of society, as discussed above, but also on the part of the innovator. Geoffrey Moore (1991) argues that contrary to the market for early adopters and insiders, who appreciate new technologies development despite their shortcomings, mainstream markets and wider stakeholders have a strong interest in the benefits and robustness of new technologies, and are not interested in the technology as such. When the technology reaches out to larger markets and has a larger impact on society, mainstream markets and wider stakeholders have a stronger influence on the final success of the innovation. But the transition from early adopters to mainstream markets is anything but smooth since the interests of the two groups are highly diverging. Thus apart from uncertainties resulting from the technology development itself, the ways in which the innovator has to communicate to mainstream markets and wider stakeholders is significantly different. This notion is further developed in management studies literature through various streams of research, such as stakeholder engagement, constructive technology assessment (CTA), CSR and organisational legitimacy.

\section{Firm strategies to deal with responsible innovations}

Stakeholder engagement is a management practice to involve stakeholders in a positive manner in business activities (Greenwood, 2007). Through their involvement, the stakeholders who may be affected by the decision of the company can express their voice, benefits and concerns regarding the organisations operations. Although it is discussed that stakeholder engagement will help to develop more responsible innovations (Von Schomberg, 2013), some scholars argue that stakeholders tend to focus on their own interests instead of building mutual understanding and consensus (Blok and Lemmens, 2015; Kaptein and Tulder, 2003). It is therefore more likely that the outcome of stakeholder engagement will increase the societal acceptance of new technologies, rather than its contribution to a shared objective of the innovation process (Stirling, 2008). This calls for more understanding of how the stakeholder dialogue paradox (Blok, 2014) can be addressed in the development of breakthrough innovations and how the willingness of sharing information can help developing more responsible innovations.

One of the major issues in this field is the integration of socio-ethical dimensions in the innovation process itself. Various conceptual frameworks such as stage-gate approaches (Jones, 1991) and open innovation approaches (Chesbrough, 2003) have been developed, but they often lack a reflection on responsibility and stakeholder inclusion (Owen et al., 2013). One approach to consider the responsibility of the innovator toward stakeholders is CTA, in which the early phase of innovation development is used to identify their impact on society. CTA addresses social issues around technology development by influencing design practices (Schot and Rip, 1997). CTA also attempts to broaden the design of new technologies by including feedback loops into the actual construction of new technologies. Similarly, foresight studies and future studies are methods to forecast the kind of impacts of new technologies, the role they play in future societies, and the additional technologies, which are needed in the future. They help to build scenarios and early warning signals about which scenario is, or will be, the dominant one and in which direction society evolves (Botterhuis et al., 2010).

In a broader scope of innovation development, scholars have developed the CSR approach (Caroll, 1999), which addresses the responsibility of organisations toward stakeholders in terms of accountability and liability. The notion of organisational responsibility builds on the idea that when organisations make decisions that affect others, 
e.g. society, this makes them responsible for the outcomes of those decisions (Pedersen, 2010). Research on CSR has brought a large array of models that provide understanding how organisations incorporate business ethics, corporate citizenship, and environmental sustainability. Although responsible innovation may not be identified with CSR (Pavie et al., 2014), these models can also help to further develop the concept of Responsible Innovation in the private sector (Pellé and Reber, 2015).

While the CSR approach has a focus on responsibility, scholars have also focused on the absence of external legitimacy for new business activities (Aldrich, 1999). Aldrich discusses these constrains from a population ecology point of view. The population ecology view addresses that initial resources may have enduring effect on the external endorsement of the new activities (Hannan, 1989; Hannan and Freeman, 1984). Studies in the field of legitimacy have focussed on a typology of legitimization activities (Delmar and Shane, 2004), explored the conceptual theory of legitimization (Suchman, 1995; Zimmerman and Zeitz, 2002), or mention the role of legitimization as a critical factor for the success of innovations (Scholten et al., 2001; Star and McMillan, 1990). Legitimacy has been examined on two levels: (1) at the level of populations or classes of organizations (Carroll and Hannan, 1989) and (2) at the level of individual organizations (Dowling and Pfeffer, 1975; Suchman, 1995). Regarding the legitimacy at the level of organizations the social definition of Suchman (1995) is often followed: 'legitimacy is a generalized perception or assumption that the actions of an entity are desirable, proper, or appropriate within some socially constructed system of norms, values, beliefs and definitions'. Based on this general definition, Suchman distinguishes three types of legitimacy: pragmatic, moral and cognitive. An organization's most immediate audience provides pragmatic legitimacy (Suchman, 1995). Moral legitimacy refers to a normative evaluation of the organization and its activities by the larger society (Aldrich and Fiol, 1994). The third dimension of legitimacy is the cognitive. Cognitive legitimacy is rooted in the taken-for-granted account that stems from social factors on cognitions and information that are embedded in the socio-cultural and organizational landscape (Aldrich, 1999; Powell and DiMaggio, 1991). These legitimation strategies may also help to better understand how small firms and start-ups are engaging in responsible innovation practices in order to be more successful at exploiting their new technological innovations.

These various developments may inform a concept of responsible innovation, which is applicable in the private sector, and help to understand how companies develop new breakthrough technologies and embed them in society.

\section{The contributions in this special issue}

Pelle and Reber's article, 'Responsible innovation in the light of moral responsibility', discusses the concept of Responsible Innovation from a CSR perspective (Pelle and Reber, 2015). They argue that relatively few scholars in the field of responsible innovation have related responsible Innovation to the CSR approach, which has been developed in detail over the last decade. Following the analysis of CSR and its relation to responsibility, they propose a conceptual mapping of responsibility in ten different meanings. These are drawing on philosophical thinking and give directions for responsible innovation to develop a more meaningful understanding of the concept, both in negative as well as in positive terms.

In his article titled 'Innovation process and ethics in technology: an approach to ethical (responsible) innovation governance', Nathan (2015) investigates a process model of responsible innovation. His research draws on innovation process models such as stage-gate, open innovation and other circular models and develops an approach to ethical innovation governance that includes ethical concerns and dilemmas from various stakeholders' perspectives. The innovation model of responsible innovation governance provides for each phase of development further understanding of how trust and legitimacy among various networks of stakeholders emerges and are embedded in ethical decision-making processes.

Flipse et al. (2015) continue this thinking of how Responsible Innovation can be implemented in the decision making process of firms and they developed a project management tool. Their article, 'Operationalizing responsible research \& innovation in industry through decision support in innovation practice' uses empirical data from the Wageningen innovation assessment toolkit questionnaire and analyse that with structural equation modelling to develop a tool that can predict success chances of current projects based on changing key performance indicators score parameters that are related to the Responsible Innovation philosophy. For managers, this tool will help not only to visualise current project performance in comparison to a database of previous projects, but also estimate success scenarios based on user input.

The fourth article is presented by Blok et al. (2015). Their article, 'Stakeholder engagement for responsible innovation in the private sector: critical issues and management 
practices in the Dutch food industry' further investigates the governance of responsible innovation during the phases of innovation development using empirical data from the food industry. They focus on the challenges of stakeholder engagement that result from the different ideas stakeholders have about ethical and societal aspects of innovation practices and the societal goals it should achieve. These different ideas may bring about tensions, which limit the mutual responsiveness between stakeholders. Further analyses of interactions between stakeholders during the phases of innovation give insight into a number of critical issues regarding stakeholder engagement, which are specific to actors involved in responsible innovation in the private sector. Especially, in the first phase of innovation development, idea discovery, and the last phase, validation and market launch, they found that mutual engagement among stakeholders was strong while in the middle phase, the actual product development phase, little interaction was identified.

Finally, Scholten and van der Duin (2015) complete this special issue with their article titled 'Responsible innovation among academic spin-offs: how responsible practices help developing absorptive capacity'. They develop a conceptual model based on the four dimensions of Stilgoe et al. (2013) and disentangle these into responsible innovation practices and absorption capabilities, and investigate how responsible innovation practices relate to the firm's capability to absorb external knowledge and to exploit this knowledge in their innovations. They have some remarkable findings regarding the effect of responsible innovation practices on either potential and realized absorption capacities which open further discussion on the concept of responsible innovation among private organisations.

\section{V.E. Scholten and V. Blok}

Delft University of Technology, P.O. Box 5015, 2600 GA Delft, the Netherlands; v.e.scholten@tudelft.nl

Wageningen University, Management Studies, Hollandseweg 1, 6706 KN Wageningen, the Netherlands; vincent.blok@wur.nl

Guest editors special issue Responsible innovations in the private sector

\section{References}

Aldrich, H.E. 1999. Organizations Evolving. Sage Publications, London, UK.

Aldrich, H.E., C.M. Fiol, 1994. Fools rush in? The institutional context of industry creation. Academy of Management Review, 19(4): 645-670.
Blok, V. and P. Lemmens, 2015. The emerging concept of responsible innovation: three reasons why it is questionable and calls for a radical transformation of the concept of innovation. In: Koops, E.J., J. van den Hoven, H.A. Romijn, T.E. Swierstra and I. Oosterlaken (eds.) Responsible innovation 2: concepts, approaches, and applications. Springer, Dordrecht, the Netherlands. pp. 19-35.

Blok, V., L. Hoffmans and E. Wubben, 2015. Stakeholder engagement for responsible innovation in the private sector: critical issues and management practices in the Dutch food industry. Journal on Chain and Network Science, 15: 147-164.

Blok, V., 2014. Look who's talking: responsible innovation, the paradox of dialogue and the voice of the other in communication and negotiation processes. Journal of Responsible Innovation, 1(2): 171-190.

Botterhuis, L., P. Van der Duin, P. de Ruijter and P. van Wijck, 2010. Monitoring the future. Building an early warning system for the Dutch Ministry of Justice. Futures, 42: 454-465.

Carroll, A.B., 1999. Corporate social responsibility: evolution of a definitional construct. Business and Society, 38: 268-295.

Carrol, G. and M. Hannan, 1989. Density dependence in the evolution of populations of newspaper organizations. American Sociological Review, 54: 524-541.

Chesbrough, H., 2003. Open Innovation: the new imperative for creating and profiting from technology. Harvard Business School Press, Boston, MA, USA.

Collingridge, D., 1980. The social control of technology. Open University Press, Milton Keynes, UK.

Delmar, F. and S. Shane, 2004. Legitimating first: organizing activities and the survival of new ventures. Journal of Business Venturing, 19: 385-410.

Dowling, J. and J. Pfeffer, 1975. Organizational legitimacy - social values and organizational behavior. Pacific Sociological Review, 18(1): 122-136.

European Commission, (2011). Communication from the Commission to the European Parliament, the Council, the European Economic and Social Committee and the Committee of the Regions. Available at: http://tinyurl.com/pvshk8o.

Flipse, S.M., K.H. Van Dam, J. Stragier, J.T.J.C. Oude Vrielink and M.C.A. Van der Sanden, 2015. Operationalizing responsible research \& innovation in industry through decision support in innovation practice. Journal on Chain and Network Science, 15: 135-146.

Greenwood, M., 2007. Stakeholder engagement: beyond the myth of corporate responsibility. Journal of Business Ethics, 74: 315-327.

Groves, C., 2006. Technological futures and non-reciprocal responsibility. International Journal of the Humanities, 4: 57-61.

Hannan, M.T., 1989. Organizational ecology. Harvard University Press, Cambridge, MA, USA.

Hannan, M.T. and F. Freeman, 1984. Structural inertia and organizational change. American Sociological Review, 49: 149-164. 
Jones, T.M., 1991. Ethical decision making by individuals in organizations: an issue contingent model. The Academy of Management Review, 16(2): 366-395.

Kaptein, M. and R. van Tulder, 2003. Toward effective stakeholder dialogue. Business and Society Review, 108(2): 203-224.

Life, 1945. Mystery town cradled bomb: 75,000 in Oak Ridge, TN worked hard and wondered long about their secret job. Life. 20 August 1945. p. 94.

Moore, G.A., 1991. Crossing the chasm: marketing and selling hightech goods to mainstream customers. Harper Business, New York, NY, USA.

Nathan, G. 2015. Innovation process and ethics in technology: an approach to ethical (responsible) innovation governance. Journal on Chain and Network Science, 15: 119-134.

Nuclear Energy Agency (NEA), 1993. Spin-off technologies developed through nuclear activities. Organization for Economic Co-operation and Development (OECD), Paris, France.

Owen, R., J. Stilgoe, P. Macnaghten, M. Gorman, E. Fisher and D. Guston, 2013. A framework for responsible innovation. In: Owen, R., J. Bessant and M. Heintz (eds.) Responsible Innovation. John Wiley and Sons Ltd, New York, NY, USA.

Pavie, X., V. Scholten and D. Carthy, 2014. Responsible innovation: from concept to practice. World Scientific, Singapore, Singapore.

Pedersen, E.R., 2010. Modelling CSR: how managers understand the responsibilities on business toward society. Journal of Business Ethics, 91(2): 155-166.

Pelle, S. and B. Reber, 2015. Responsible innovation in the light of moral responsibility. Journal on Chain and Network Science, 15: 107-118.

Pless, N, T. Maak and D.A. Waldman, 2012. Different approaches toward doing the right thing: mapping the responsibility orientations of leaders. Academy of Management Perspectives, 26(4): 51-65.

Powell, W.W. and P.J. DiMaggio (eds.), 1991. The new institutionalism in organizational analysis. University of Chicago Press, Chicago. IL, USA.
Scholten, V.E., S.W.F. Omta and T. Elfring, 2001. The significance of parenthood: the social capital of the parent organization and the entrepreneurial outcome. In: Kuopusjärvi, P. (ed.) Proceedings of the Rent XV Conference, Turku, Finland, vol.2: Research on Entrepreneurship, pp. 200-211.

Scholten, V.E. and P.A. Van der Duin, 2015. Responsible innovation among academic spin-offs: how responsible practices help developing absorptive capacity. Journal on Chain and Network Science, 15: 165-180.

Schot, J. and A. Rip, 1997. The past and future of constructive technology assessment. Technological Forecasting and Social Change, 54: 251-268.

Starr, A.S. and I.C. MacMillan, 1990. Resource cooptation via social contracting resource acquisition strategies for new resources. Strategic Management Journal, 11: 79-92.

Stilgoe, J., R. Owen and P. Macnaghten, 2013. Developing a framework for responsible innovation. Research Policy, 42(9): 1568-1580.

Stirling, A., 2008. 'Opening up' and 'closing down': power, participation, and pluralism in the social appraisal of technology. Science Technology and Human Values, 33(2): 262-294.

Suchman, M.C., 1995. Managing legitimacy: strategic and institutional approaches. Academy of Management Review, 20(3): 571-610.

Van den Hoven, J., G.-J., Lokhorst and I. van de Poel, 2012. Engineering and the problem of moral overload. Science and Engineering Ethics, 18(1): 143-155.

Von Schomberg, R., 2013. A vision of responsible research and innovation. In: Owen, R., J. Bessant and M. Heintz (eds.) Responsible Innovation. John Wiley and Sons Ltd, New York, NY, USA.

Waldman, D.A. and B. Galvin, 2008. Alternative perspectives of responsible leadership. Organizational Dynamics, 37(4): 327-341.

Waldman, D.A. and D. Siegel, 2008. Theoretical and practitioner letters: defining the socially responsible leader. Leadership Quarterly, 19(1): 117-131.

Zimmerman, M.A. and G.J. Zeitz, 2002. Beyond survival: achieving new venture growth by building legitimacy. Academy of Management Review, 27(3): 414-431. 
